\title{
Relationships of physical fitness and obesity with metabolic risk factors in children and adolescents: Chungju city cohort study
}

\author{
Hyo Jin Kim, MD', \\ Kyu-Jin Lee, MD', \\ Yeon Jin Jeon, $M D^{\prime}$, \\ Moon Bae Ahn, MD', \\ In Ah Jung, $\mathrm{MD}^{1}$, \\ Shin Hee Kim, MD', \\ Won-Kyoung Cho, MD, PhD', \\ Kyoung Soon Cho, MD', \\ So Hyun Park, MD, PhD', \\ Min Ho Jung, MD, PhD', \\ Jin-Hee Lee, $\mathrm{PhD}^{2}$, \\ Byung-Kyu Suh, MD, PhD' \\ ${ }^{1}$ Department of Pediatrics, College \\ of Medicine, The Catholic University \\ of Korea, Seoul, ${ }^{2}$ Catholic Institute of \\ U-Healthcare, Institute of Biomedical \\ Industry, The Catholic University of \\ Korea, Seoul, Korea
}

Received: 12 August, 2015 Revised: 30 September, 2015 Accepted: 15 October, 2015

\footnotetext{
Address for correspondence: Byung-Kyu Suh, MD, PhD

Department of Pediatrics, The Catholic University of Korea, Seoul St. Mary's Hospital, 222 Banpo-daero, Seocho-gu, Seoul 06591, Korea

Tel: +82-2-2258-6185,

Fax: +82-2-532-6185,

E-mail: suhbk@catholic.ac.kr Address for co-correspondence:

Jin-Hee Lee, PhD

Catholic Institute of U-healthcare, Institute of Biomedical Industry, The Catholic University of Korea, 222 Banpo-daero, Seocho-gu, Seoul 06591, Korea

Tel: +82-2-2258-8298,

Fax: +82-2-594-2704,

E-mail:jheelee@catholic.ac.kr
}

Purpose: The purpose of this study was to investigate the relationships of physical fitness and obesity with metabolic risk factors in children and adolescents.

Methods: This cohort study was conducted in Chungju city, South Korea. Total 843 subjects were enrolled, including 193 elementary school 4th grade male (E4M), 189 elementary school 4th grade female (E4F) and 461 male-middle school students (M1M). The subjects were also classified into 2 groups by body mass index; normal weight (NW) group and overweight included obesity (OW/OB) group. Physical fitness was measured by shuttle run (cardiorespiratory fitness, CRF), sit and reach (flexibility), handgrip strength (muscular strength) and stand long jump (agility).

Results: The prevalence of OW/OB was respectively $33.7 \%$ (65 of 193) among E4M, $28.6 \%$ (54 of 189) among E4F, and 28.0\% (129 of 461) among M1M. Hematocrit, white blood cell, triglyceride, low-density lipoprotein, insulin, homeostasis model assessment of insulin resistance, systolic and diastolic blood pressure were higher, while high-density lipoprotein were lower in the OW/OB group than in the NW group. The OW/OB group presented significantly lower CRF $(P<0.01)$ and lower agility, but higher muscular strength compared with NW group. CRF was negatively correlated with obesity indices and metabolic risk factors. After adjustments for potential confounders, odds ratios for 4th-5th grade CRF of OW/OB compared NW in the E4M, E4F, M1M, were $7.38(95 \% \mathrm{Cl}, 3.24-16.83)$, 4.10 (95\% Cl, 1.83-9.18), $16.06(95 \% \mathrm{Cl}, 8.23-31.00)(P<0.01)$.

Conclusion: Our study has shown that CRF has negative correlation with OW/OB in children and adolescents of Chungju city. We suggest that improvement of CRF through regular physical activity would be an important method for reducing the metabolic risks of childhood obesity.

Keywords: Obesity, Overweight, Child, Adolescent, Physical fitness

\section{Introduction}

The prevalence of childhood obesity has been rapidly increasing worldwide for the past 30 years and considered as a serious public health issue ${ }^{1,2}$. In Korea, Oh et al. ${ }^{3)}$ reported the prevalence of childhood obesity, by using data from the National Growth Survey conducted in 1997 and 2005, that was increased 1.7 folds from $5.8 \%$ in 1997 to $9.7 \%$ in 2005. Also, the prevalence of childhood overweight or obesity was increased 1.5 folds from $13.0 \%$ in 1997 to $19.0 \%$ in 2005 . Childhood obesity is a risk factor for cardiovascular disease and metabolic syndrome (MS) in adulthood and thus affects morbidity and mortality in later life ${ }^{2,4-8)}$. Up to $80 \%$ of obese children continued to become obese and thus affects morbidity and mortality in adult life ${ }^{1)}$.

Recently, reduced physical activities were considered as one of the primary causes of 
the childhood obesity ${ }^{1,9)}$. Physical fitness is defined as "the ability to carry out daily tasks without fatigue." Health-related components include cardiorespiratory fitness (CRF), muscular endurance, muscular strength, and flexibility. Motor-related fitness includes power, agility, and balance ${ }^{10-12}$. Several studies have reported the negative association of physical fitness with childhood obesity ${ }^{10,13-15)}$. Also, evidence from previous studies suggests that low CRF is a major risk factor of metabolic abnormalities, and also known as an independent and strong predictor of $\mathrm{MS}^{16,17}$. In Korea, some studies have been reported the negative association between obesity and physical fitness ${ }^{18)}$. However, there are a few reports which examined the association befigtween metabolic risk factors and physical fitness. The purpose of the present cohort study is to determine the association of CRF with obesity and metabolic risk profiles in Korean elementary and middle school students.

\section{Materials and methods}

\section{Subjects}

This study included 404 elementary school 4 th grade school students, aged 9-10 years (203 males and 201 females) and 480 male-middle 1st grade school students, aged 12-13 years from Chungju city, South Korea. The study subjects were recruited from 3 elementary and 2 middle schools. The data collection was carried out between April 2014 and May 2014 in the participated schools. The inclusion criteria were (1) both the parent or guardian and children gave their written informed consent; (2) the child had to participate in physical activity test; (3) having $\geq 5$ th percentile of body mass index (BMI), according to the age- and gender-specific reference values of the 2007 Korean National Growth charts. Of these 884 subjects, 41 were excluded due to incomplete information or having below 5 th percentile of BMI according to age and sex. Ultimately, our study population included 382 elementary school 4 th grade students (193 males, 189 females) and 461 male-middle school 1 st grade male students. Among them, only 227 students, which composed of 88 elementary school student ( 35 males, 53 females) and 139 male-middle school students, gathered from 2 elementary and 1 middle school, were performed laboratory examination. Approval for this study was obtained from the Catholic University of Korea, College of Medicines Institutional Review Board.

\section{Measurements}

Height to the nearest $0.1 \mathrm{~cm}$ using a BIKI 200 (Jawon Medical, Daejeon, Korea). Weight and body fat percentage were assessed using bioelectrical impedance analysis method (IOI353, Jawon Medical). Both height and weight were measured with participants in light clothing and without shoes. BMI was calculated as the weight in kilograms divided by height in meters squared. Waist circumference (WC) and blood pressure
(BP) measurement were performed by trained nurses. WC was measured between the lowest rib and the middle of the iliac crest to the nearest $0.1 \mathrm{~cm}$ in a standing position with his/her both feet close. Waist to height ratio (WHtR) was calculated as the waist $(\mathrm{kg})$ divided by the height $(\mathrm{cm})$ from obtained data ${ }^{19)}$.

$\mathrm{BP}$ was measured while subjects were in a sitting position following a 5-minutes rest period. Systolic and diastolic BP were measured, by a mercury sphygomomanometer (CL4114, Young-Pung Medical, Seoul, Korea) with a proper sized cuff that covers two-thirds of the upper arm. BP was measured 2 times, average was used in the analysis. To assess serum levels of biochemical markers, blood samples were obtained from the antecubital veins of the subjects following an overnight, 10 hours fast. Blood specimens were sampled by trained nurses. Complete blood count (CBC) were measured with an XN-9000 (Sysmex, Kobe, Japan): XN 10×8 (CBC+differential count) and serum levels of fasting blood sugar (FBS), total cholesterol (TC), triglyceride (TG), high-density lipoprotein (HDL) cholesterol, and low-density lipoprotein (LDL) cholesterol were measured using an enzymatic method with an Cobas 8000 C702 (Roche, Mannheim, Germany). Insulin levels were measured with an Cobas 8000 e602 (Roche) with a electrochemiluminescence immunoassay. All laboratory examinations were performed by Seegene medical foundation, Korea.

\section{Study criteria}

The subjects were classified in 2 groups: (1) normal weight (NW, 5th-85th percentile); (2) overweight (OW, 85th-94th percentile, ) and obesity ( $\mathrm{OB}, \geq 95$ th percentile, ) according to the age- and gender-specific reference values of the 2007 Korean National Growth charts ${ }^{7,20)}$. According to International Diabetes Federation criteria, adolescents with abdominal obesity (WC $\geq 90$ th percentile for age and sex) and 2 or more of the following criteria: $\mathrm{TG} \geq 150 \mathrm{mg} / \mathrm{dL} ; \mathrm{HDL} \leq 40 \mathrm{mg} / \mathrm{dL}$; fasting glucose $\geq 100 \mathrm{mg} / \mathrm{dL}$; and systolic $\mathrm{BP} \geq 130 \mathrm{mmHg}$; or diastolic $\mathrm{BP} \geq 85 \mathrm{mmHg}$ were diagnosed with $\mathrm{MS}^{21)}$. Insulin resistance was determined using the homeostasis model assessment of insulin resistance (HOMA-IR=fasting glucose $[\mathrm{mmol} / \mathrm{L}] \times$ fasting insulin $[\mu \mathrm{U} / \mathrm{mL}] / 22.5)$.

\section{Physical fitness measurement}

Physical fitness was assessed using the physical activity promotion system (PAPS) of the Ministry of Education in Korea for the purpose of evaluation and exercise prescription for the increasing obesity prevalence and declining physical fitness among Korean students ${ }^{22)}$. This test is a reliable instrument to measure physical fitness in children and is a commonly used in Korea since 2009. PAPS consists of 5 tests that measure different components of fitness: $15-\mathrm{m}$ (for elementary school students) and $20-\mathrm{m}$ (for middle school students) shuttle run for CRF, sit and reach for flexibility, handgrip strength for muscular strength, stand long jump for agility, body fat percent for fatness. 
The physical fitness tests mentioned above have shown to be reliable and valid in adolescent population ${ }^{23,24)}$. The physical fitness tests were measured 2 times, the best result was used in the analysis.

The measurements were calculated by PAPS scoring system. The body's ability is scored total 100 points, calculated by summing the scores of the five components of 20 points by PAPS scoring scale. Each component is categorized 5 grades, and the higher point, which means superior fitness ability, corresponds to the lower grade. Grade 5 was matched 0-3 points, grade 4 was matched 4-7 points, grade 3 was matched $8-11$ points, grade 2 was matched $12-15$ points, grade 1 was matched 16-20 points ${ }^{22}$. Physical fitness test was performed in gymnasium of each school and measured by Welltizen (Seoul, Korea).

\section{Statistical analysis}

All statistical analyses were carried out using IBM SPSS Statistics ver. 20.0 (IBM Co., Armonk, NY, USA). Continuous variables were expressed as the mean \pm standard deviation by frequency analysis. Independent $t$-test was used for anthropometric and laboratory data analysis. Pearson correlation analysis was used for metabolic correlation of components and CRF. Simple logistic regression analysis was used for causality of $\mathrm{OW} / \mathrm{OB}$ and 4-5 grades of CRF, and multiple logistic regression used for it with adjustment of height, SBP. Odds ratio (OR) and 95\% confidence interval (CI) values for having recorded and in all statistical analysis, $P$-values of less than 0.05 were considered statistically significant.

Table 1. Anthropometric characteristics of study subjects in 3 groups $(n=843)$

\begin{tabular}{|c|c|c|c|c|c|}
\hline Variable & E4M $(n=193)$ & $E 4 F(n=189)$ & $\operatorname{M1M}(n=461)$ & $P$-value & $P$-value ${ }^{\text {b) }}$ \\
\hline Age (yr) & $9.4 \pm 0.5$ & $9.4 \pm 0.5$ & $12.3 \pm 0.5$ & NS & $<0.01$ \\
\hline Height (cm) & $140.0 \pm 6.2$ & $138.2 \pm 6.4$ & $158.7 \pm 8.0$ & NS & $<0.01$ \\
\hline Weight (kg) & $37.5 \pm 10.0$ & $36.0 \pm 8.3$ & $54.3 \pm 13.2$ & NS & $<0.01$ \\
\hline BMI $\left(\mathrm{kg} / \mathrm{m}^{2}\right)$ & $19.5 \pm 3.9$ & $18.7 \pm 3.3$ & $21.4 \pm 4.2$ & $<0.05$ & $<0.01$ \\
\hline Overweight & $35(18.1)$ & $30(15.9)$ & $69(15.0)$ & & \\
\hline Obesity & $30(16.1)$ & $24(12.7)$ & $60(13.0)$ & & \\
\hline Body fat (\%) & $13.6 \pm 8.0$ & $21.1 \pm 5.6$ & $16.2 \pm 8.7$ & $<0.01$ & $<0.01$ \\
\hline$W C(\mathrm{~cm})$ & $65.4 \pm 10.7$ & $62.2 \pm 8.5$ & $72.9 \pm 12.0$ & $<0.01$ & $<0.01$ \\
\hline WC $>90$ th percentile & $31(16.1)$ & $28(14.8)$ & $71(15.4)$ & & \\
\hline WHtR & $0.5 \pm 0.1$ & $0.5 \pm 0.1$ & $0.5 \pm 0.1$ & NS & $<0.01$ \\
\hline Metabolic syndrome & $0(0)$ & $0(0)$ & $8(1.7)$ & & \\
\hline
\end{tabular}

Values are presented mean \pm standard deviation or number (\%).

Overweight was defined as the 85th-95th percentile gender-specific BMI for age in the 2007 Korean National Growth charts; Obesity was defined $>$ the 95 th percentile.

E4M, elementary school 4th grade male students; E4F, elementary school 4th grade female students; M1M, male-middle school 1st grade students; NS, not significant; BMI, body mass index; WC, waist circumference; WHtR, waist to height ratio.

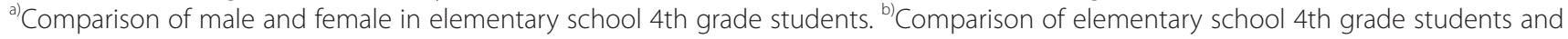
male-middle school 1st grade students.

Table 2. Clinical characteristics of 3 groups classified as normal weight and overweight including obesity $(n=843)$

\begin{tabular}{|c|c|c|c|c|c|c|c|c|c|}
\hline \multirow{2}{*}{ Variable } & \multicolumn{3}{|c|}{ E4M } & \multicolumn{3}{|c|}{ E4F } & \multicolumn{3}{|c|}{ M1M } \\
\hline & Normal & OW/OB & $P$-value & Normal & $\mathrm{OW} / \mathrm{OB}$ & $P$-value & Normal & OW/OB & $P$-value \\
\hline No. of patients & $128(66.3)$ & 65 (33.7) & & $135(71.4)$ & $54(28.6)$ & & $332(72.0)$ & $129(28.0)$ & \\
\hline Height (cm) & $136.2 \pm 5.5$ & $141.4 \pm 6.3$ & $<0.01$ & $136.8 \pm 6.3$ & $141.9 \pm 5.6$ & $<0.01$ & $157.9 \pm 8.1$ & $161.0 \pm 7.4$ & $<0.01$ \\
\hline Weight (kg) & $32.0 \pm 4.8$ & $48.5 \pm 8.6$ & $<0.01$ & $32.1 \pm 4.7$ & $46.1 \pm 6.8$ & $<0.01$ & $48.3 \pm 8.4$ & $69.9 \pm 10.3$ & $<0.01$ \\
\hline BMI $\left(\mathrm{kg} / \mathrm{m}^{2}\right)$ & $17.1 \pm 1.8$ & $24.0 \pm 2.6$ & $<0.01$ & $17.1 \pm 1.6$ & $22.9 \pm 2.8$ & $<0.01$ & $19.2 \pm 2.2$ & $26.8 \pm 2.8$ & $<0.01$ \\
\hline Body fat (\%) & $9.0 \pm 4.8$ & $22.8 \pm 4.3$ & $<0.01$ & $18.5 \pm 4.3$ & $29.2 \pm 3.7$ & $<0.01$ & $11.8 \pm 5.7$ & $27.4 \pm 3.8$ & $<0.01$ \\
\hline WC (cm) & $59.3 \pm 5.3$ & $77.4 \pm 8.3$ & $<0.01$ & $58.1 \pm 4.9$ & $72.4 \pm 6.8$ & $<0.01$ & $67.0 \pm 6.9$ & $87.9 \pm 8.6$ & $<0.01$ \\
\hline WHtR & $0.4 \pm 0.0$ & $0.5 \pm 0.1$ & $<0.01$ & $0.4 \pm 0.0$ & $0.5 \pm 0.1$ & $<0.01$ & $0.4 \pm 0.0$ & $0.5 \pm 0.1$ & $<0.01$ \\
\hline $\mathrm{SBP}(\mathrm{mmHg})$ & $109.0 \pm 9.8$ & $121.2 \pm 11.5$ & $<0.01$ & $109.0 \pm 10.3$ & $122.6 \pm 10.6$ & $<0.01$ & $113.0 \pm 10.8$ & $123.7 \pm 16.9$ & $<0.01$ \\
\hline $\mathrm{DBP}(\mathrm{mmHg})$ & $69.4 \pm 6.9$ & $77.3 \pm 9.4$ & $<0.01$ & $70.1 \pm 9.0$ & $79.5 \pm 9.3$ & $<0.01$ & $69.7 \pm 7.9$ & $72.7 \pm 11.0$ & $<0.01$ \\
\hline
\end{tabular}

Values are presented as number (\%) or mean \pm standard deviation.

E4M, elementary school 4th grade male students; E4F, elementary school 4th grade female students; M1M, male-middle school 1st grade students; OW/OB, overweight and obesity; BMI, body mass index; WC, waist circumference; WHtR, waist to height ratio; SBP, systolic blood pressure; DBP, diastolic blood pressure; CRF, cardiorespiratory fitness; NS, not significant. 
Table 3. Laboratory data of 3 groups classified as normal weight and overweight including obesity $(n=227)$

\begin{tabular}{|c|c|c|c|c|c|c|c|c|c|}
\hline \multirow{2}{*}{ Variable } & \multicolumn{3}{|c|}{$\mathrm{E} 4 \mathrm{M}$} & \multicolumn{3}{|c|}{ E4F } & \multicolumn{3}{|c|}{$\mathrm{M} 1 \mathrm{M}$} \\
\hline & Normal & $\mathrm{OW} / \mathrm{OB}$ & $P$-value & Normal & $\mathrm{OW} / \mathrm{OB}$ & $P$-value & Normal & $\mathrm{OW} / \mathrm{OB}$ & $P$-value \\
\hline No. of patients & $23(65.7)$ & $12(34.3)$ & & $37(69.8)$ & $16(30.2)$ & & $104(74.8)$ & $35(25.2)$ & \\
\hline $\mathrm{Hb}(\mathrm{g} / \mathrm{dL})$ & $13.9 \pm 0.7$ & $13.7 \pm 0.6$ & NS & $13.9 \pm 0.7$ & $13.8 \pm 0.6$ & NS & $14.4 \pm 1.0$ & $14.5 \pm 0.8$ & NS \\
\hline Hct (\%) & $42.0 \pm 2.1$ & $41.3 \pm 1.4$ & NS & $42.0 \pm 2.1$ & $42.0 \pm 1.7$ & NS & $42.7 \pm 2.5$ & $43.7 \pm 2.4$ & $<0.05$ \\
\hline WBC $\left(10^{9} / L\right)$ & $5.5 \pm 1.0$ & $7.2 \pm 1.2$ & $<0.01$ & $6.6 \pm 2.1$ & $6.7 \pm 1.7$ & NS & $6.3 \pm 1.4$ & $6.9 \pm 1.3$ & $<0.05$ \\
\hline FBS (mg/dL) & $87.9 \pm 5.6$ & $86.3 \pm 3.9$ & NS & $86.8 \pm 7.7$ & $83.3 \pm 5.7$ & NS & $88.1 \pm 5.5$ & $89.8 \pm 7.6$ & NS \\
\hline TC (mg/dL) & $166.2 \pm 27.6$ & $181.0 \pm 33.7$ & NS & $172.2 \pm 19.5$ & $157.3 \pm 26.3$ & NS & $153.8 \pm 24.2$ & $160.4 \pm 27.9$ & NS \\
\hline TG (mg/dL) & $77.8 \pm 39.2$ & $101.8 \pm 42.0$ & NS & $84.5 \pm 32.7$ & $91.0 \pm 38.1$ & NS & $71.7 \pm 33.9$ & $105.7 \pm 49.4$ & $<0.01$ \\
\hline $\mathrm{HDL}(\mathrm{mg} / \mathrm{dL})$ & $60.7 \pm 8.6$ & $58.1 \pm 12.2$ & NS & $63.2 \pm 13.9$ & $51.8 \pm 13.2$ & $<0.01$ & $56.1 \pm 11.0$ & $47.0 \pm 11.0$ & $<0.01$ \\
\hline LDL (mg/dL) & $90.4 \pm 28.3$ & $102.4 \pm 27.3$ & NS & $92.1 \pm 18.4$ & $87.4 \pm 21.3$ & NS & $83.4 \pm 22.5$ & $92.4 \pm 21.9$ & $<0.05$ \\
\hline Insulin ( $\mu \mathrm{U} / \mathrm{mL})$ & $7.7 \pm 4.4$ & $11.7 \pm 5.1$ & $<0.05$ & $9.8 \pm 4.8$ & $13.3 \pm 6.6$ & NS & $11.1 \pm 6.8$ & $24.6 \pm 25.8$ & $<0.01$ \\
\hline HOMA-IR & $1.7 \pm 1.1$ & $2.5 \pm 1.2$ & NS & $2.2 \pm 1.2$ & $2.8 \pm 1.4$ & NS & $2.4 \pm 1.6$ & $5.7 \pm 6.8$ & $<0.01$ \\
\hline
\end{tabular}

Values are presented as number (\%) or mean \pm standard deviation

E4M, elementary school 4th grade male students; E4F, elementary school 4th grade female students; M1M, male-middle school 1st grade students; OW/OB, overweight and obesity; Hb, hemoglobin; Hct, hematocrit; WBC, white blood cell; FBS, fasting blood sugar; TC, total cholesterol; TG, triglyceride; HDL, high-density lipoprotein; LDL, low-density lipoprotein; HOMA-IR, homeostasis model assessment for insulin resistance; NS, not significant.

Table 4. Correlation between cardiorespiratory fitness and metabolic risk factors

\begin{tabular}{|c|c|c|c|c|c|c|}
\hline \multirow{2}{*}{ Variable } & \multicolumn{2}{|c|}{ E4M $(n=193)$} & \multicolumn{2}{|c|}{$E 4 F(n=186)$} & \multicolumn{2}{|c|}{$\operatorname{M1M}(n=461)$} \\
\hline & $R$ & $P$-value & $R$ & $P$-value & $R$ & $P$-value \\
\hline BMI $\left(\mathrm{kg} / \mathrm{m}^{2}\right)$ & -0.57 & $<0.01$ & -0.40 & $<0.01$ & -0.54 & $<0.01$ \\
\hline WC (cm) & -0.57 & $<0.01$ & -0.35 & $<0.01$ & -0.54 & $<0.01$ \\
\hline WHtR & -0.59 & $<0.01$ & -0.31 & $<0.01$ & -0.59 & $<0.01$ \\
\hline $\mathrm{SBP}(\mathrm{mmHg})^{\mathrm{a})}$ & -0.20 & $<0.01$ & -0.28 & $<0.01$ & -0.09 & NS \\
\hline $\mathrm{DBP}(\mathrm{mmHg})^{\mathrm{a})}$ & -0.16 & $<0.05$ & -0.29 & $<0.01$ & -0.02 & NS \\
\hline $\mathrm{FBS}(\mathrm{mg} / \mathrm{dL})^{\mathrm{a})}$ & -0.36 & NS & 0.08 & NS & -0.16 & NS \\
\hline $\mathrm{TG}(\mathrm{mg} / \mathrm{dL})^{\mathrm{a})}$ & -0.24 & NS & -0.36 & $<0.01$ & -0.39 & $<0.01$ \\
\hline $\mathrm{HDL}(\mathrm{mg} / \mathrm{dL})^{\mathrm{a})}$ & 0.46 & $<0.01$ & 0.29 & $<0.05$ & 0.23 & $<0.01$ \\
\hline
\end{tabular}

E4M, elementary school 4th grade male students; E4F, elementary school 4th grade female students; M1M, middle school first grade male students; BMI, body mass index; WC, Waist circumference; WHtR, Waist to height ratio; SBP, systolic blood pressure; DBP, diastolic blood pressure; FBS, fasting blood sugar; TG, triglyceride; $\mathrm{HDL}$, high-density lipoprotein; NS, not significant.

a) Laboratory data were analyzed for only 227 subjects whereas total subject was 843 .

\section{Results}

The clinical characteristics of the study subjects are listed in Table 1 . The prevalence of $\mathrm{OW} / \mathrm{OB}$ was respectively $33.7 \%$ (65 of 193) among the E4M, 28.6\% (54 of 189) among the E4F, and 28.0\% (129 of 461) among the M1M. The prevalence of abdominal obesity was $16.1 \%$ (31 of 193) among the E4M, $14.8 \%$ (28 of 189) among the E4F, and $15.4 \%$ (71 of 461) among the M1M. The prevalence of MS was $1.7 \%$ ( 8 of 474 ) among the M1M, whereas none of the elementary school students satisfied the MS criteria. In elementary school students, BMI $\left(19.5 \pm 3.9 \mathrm{~kg} / \mathrm{m}^{2}\right.$ vs. $\left.18.7 \pm 3.3 \mathrm{~kg} / \mathrm{m}^{2}, P<0.05\right)$, WC $(65.4 \pm 10.7 \mathrm{~cm}$ vs. $62.2 \pm 8.5 \mathrm{~cm}, P<0.01)$ were significantly higher in male than female. However, body fat percentage was significantly lower in male than female $(13.6 \% \pm 8.0 \%$ vs. $21.1 \% \pm 5.6 \%, P<0.01)$. There were no significant differences in the mean age, height, body weight and WHtR of the sex. In male students, height (158.7 \pm 8.1 cm vs. $140.0 \pm 6.2 \mathrm{~cm}, P<0.01)$, weight $(54.3 \pm 13.2 \mathrm{~kg}$ vs. $37.5 \pm 10.0$ $\mathrm{kg}, P<0.01)$, BMI $\left(21.4 \pm 4.2 \mathrm{~kg} / \mathrm{m}^{2}\right.$ vs. $\left.19.5 \pm 3.9 \mathrm{~kg} / \mathrm{m}^{2}, P<0.01\right)$, body fat percentage $(16.2 \% \pm 8.7 \%$ vs. $13.6 \% \pm 8.0 \%, P<0.01)$, and WC $(72.9 \pm 12.0 \mathrm{~cm}$ vs. $65.4 \pm 10.7 \mathrm{~cm}, P<0.01)$ were significantly higher in middle school than elementary school students.

The comparison of clinical characteristics between the OW/ $\mathrm{OB}$ and NW groups are shown in Table 2. The OW/OB group showed significantly higher levels for height, weight, BMI, body fat percentage, WC, WHtR, and systolic and diastolic BP than in the NW group.

The comparison of laboratory data between the $\mathrm{OW} / \mathrm{OB}$ and NW groups are shown in Table 3. The OW/OB group showed significantly higher levels for hematocrit in M1M, white blood cell count in the E4M and M1M; TG in the M1M; LDL in the M1M; serum insulin level in the E4M and M1M; HOMA-IR in the M1M than the NW group. HDL cholesterol was significantly lower in the OW/OB than in the NW group for E4F and M1M. No significant difference was shown in hemoglobin, FBS, TC in comparison of the OW/OB and NW groups.

The comparison of physical fitness data between the OW/ $\mathrm{OB}$ and NW groups are shown in Fig. 1. The OW/OB had a significantly lower CRF and agility, but higher muscular strength compared with NW group. There were no significant differences in the flexibility.

The Pearson correlation between CRF and the components of MS was shown in Table 4. In the E4M, E4F, and M1M groups, BMI ( $R=-0.57$ vs. $R=-0.40$ vs. $R=-0.54)$, WC $(R=-0.57$ vs. $R=-0.35$ vs. $R=-0.54)$, and WHtR $(R=-0.59$ vs. $R=-0.31$ vs. $R=-0.59)$ were significantly inversely correlated with CRF. Among the E4M and E4F, SBP ( $R=-0.20$ vs. $R=-0.28)$ and DBP ( $R=-0.16$ vs. $R=-0.29)$ were significantly inversely correlated with CRF $(P<0.01)$. TG level showed significant negative correlations only in the females $(R=-0.36, P<0.01)$, whereas 
Table 5. Logistic regression analysis for overweight/obesity with 4-5 grades of cardiorespiratory fitness

\begin{tabular}{|c|c|c|c|c|c|c|}
\hline \multirow{2}{*}{ Variable } & \multicolumn{3}{|c|}{ Model $1^{\text {a) }}$} & \multicolumn{3}{|c|}{ Model $2^{\text {b) }}$} \\
\hline & OR & $95 \% \mathrm{Cl}$ & $P$-value & OR & $95 \% \mathrm{Cl}$ & $P$-value \\
\hline E4M $(n=56)$ & 6.70 & $3.39-13.28$ & $<0.01$ & 7.38 & $3.24-16.83$ & $<0.01$ \\
\hline $\mathrm{E} 4 \mathrm{~F}(\mathrm{n}=59)$ & 4.77 & $2.41-9.42$ & $<0.01$ & 4.10 & $1.83-9.18$ & $<0.01$ \\
\hline $\operatorname{M1M}(n=241)$ & 11.64 & $6.39-21.17$ & $<0.01$ & 16.06 & $8.32-31.00$ & $<0.01$ \\
\hline
\end{tabular}

OR, odds ratio; $\mathrm{Cl}$, confidence interval; E4M, elementary school 4th grade male students; E4F, elementary school 4th grade female students; M1M, middle school first grade male students.

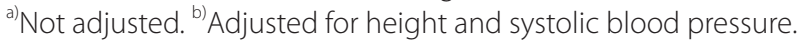
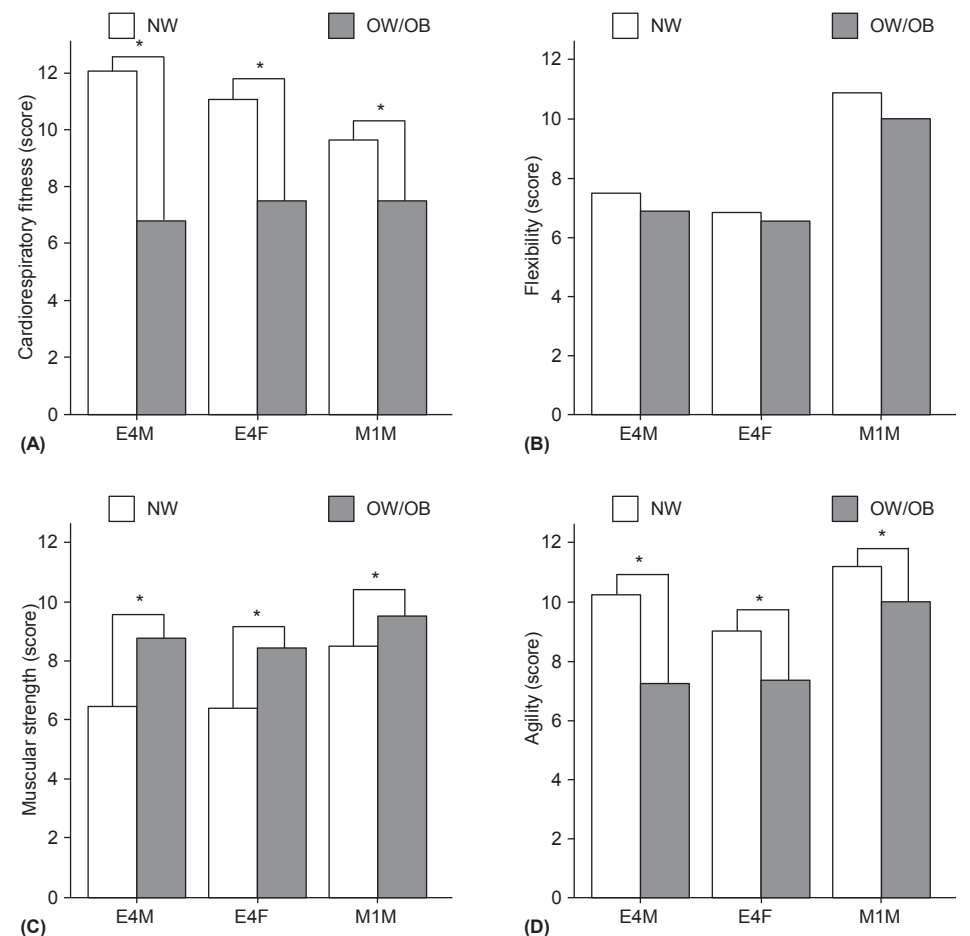

Fig. 1. The average score of components of physical fitness in normal weight vs. overweight including obesity according to each groups (E4M, E4F, M1M). (A) Cardiovascular fitness. (B) Flexibility. (C) Muscular strength. (D) Agility. NW, normal weight and obesity; E4M, elementary school 4th grade male students; E4F, elementary school 4th grade female students; M1M, middle school 1st grade male students. ${ }^{*} P<0.05$.

HDL cholesterol showed a significant positive correlation only in the male students $(R=0.46, P<0.01)$. There were no significant differences in the FBS. In the M1M, TG $(R=-0.39, P<0.01)$ were significantly inversely correlated with CRF, whereas $\operatorname{HDL}(R=0.23, P<0.01)$ levels had shown significantly positive correlation with CRF.

The results of the logistic regression analyses between 4th-5th grade CRF and obesity was shown in Table 5. After adjustments for height and $\mathrm{BP}$, the $\mathrm{OR}$ of the $\mathrm{OW} / \mathrm{OB}$ for 4 th-5th grade CRF in the E4M, E4F and M1M were 7.38 (95\% CI, 3.24-16.83; $P<0.01$ ), 4.10 (95\% CI, 1.83-9.18; $P<0.01$ ), 16.06 (95\% CI, 8.32$31.00 ; P<0.01)$, respectively.

\section{Discussion}

We examined the association between physical fitness and obesity with metabolic risk factors among elementary and middle school students from the city of Chungju. Current clinical guidelines indicate a role of physical activity in the management and prevention of childhood obesity ${ }^{1)}$. CRF, an objective marker of recent physical activity patterns, is stronger than other physical fitness test as a predictor of health outcomes ${ }^{17}$.

Interestingly, findings from our study demonstrate that almost $30 \%$ of elementary and middle school students in Chungju city measured above the 85th percentile of BMI. This result was much larger proportion than the known value of almost 20\% for 2 previous studies based on Korea Nutrition Examination survey from 10-19 and 12-19 years of age group ${ }^{25,26)}$, but a similar rate compared to a few studies from elementary school 4th grade students alone (32.8\% in male, $24.7 \%$ in female $)^{27}$ and middle school 1st grade male students alone $(26.4 \%)^{28}$. Because of the different ranges of sex and age and diagnostic criteria 
for obesity used in these studies, cross-comparison would be challenging. However, these results suggest that further studies are necessary to demonstrate that higher prevalence of obesity in school aged children compared to overall children and adolescents.

In the present study, we observed that CRF was lower and muscular strength was higher in the OW/OB group in comparison to the NW group. After adjustments for potential confounders, odds ratios for 4 th -5 th grade CRF of OW/ OB compared NW in the E4M, E4F, M1M, were 7.38 (95\% CI, 3.24-16.83), 4.10 (95\% CI, 1.83-9.18), 16.06 (95\% CI, 8.23-31.00) $(P<0.001)$. These findings were consistent with the several previous reports such as 9,414 Belgian girls 6 to 18 years of age ${ }^{299}, 209$ Scotland adolescents 15 to 17.5 years of age $e^{30)}$, 726 Korean college male students ${ }^{11}, 2,474$ Spain adolescents ${ }^{311}$. It has been suggested that these lower performance in obese children are probably due to the fact that their excess body fat is an extra load to be moved when they perform weight-bearing task (shuttle run, sit-up, standing long jump, and bent-arm sling $)^{10)}$. In another suggestion, obese children and adolescents have a greater tendency to avoid weight-bearing activities than the NW, thus the deficiency of this experience can lead to poor performance ${ }^{32)}$. The reason why muscular strength is high in obese children and adolescents would be explained as their increased fat-free mass. Fat-free mass increases as amount of excessive adiposity, and this supports the extra load ${ }^{10)}$. In other studies that the separate assessment for muscular strength in the upper and lower extremities was done, muscular strength for upper extremities was greater whereas lower extremity explosive strength was lower in the $\mathrm{OB}$ group in the comparison to the NW group ${ }^{25,33)}$. Reduction in trunk and lower extremity strength cause musculoskeletal fatigue and can increase the risk of injury during activities ${ }^{34)}$.

CRF was lower in male middle school students than elementary school students in this study. This finding suggests that increasing age is likely to be associated with decreased CRF. Further studies will be necessary to investigate the influence of age on the CRF.

Regular physical activity affects weight loss and maintenance in $\mathrm{OW} / \mathrm{OB}$ group; increases energy capacity; controls blood glucose level, and increases insulin sensitivity by forming a channel to facilitate the inflow of blood glucose to the inside of the cells by transferring insulin-dependent glucose transport (GLUT-4) to the cell surface according to the change of insulin signaling during muscle contraction; and contributes to the normalization of metabolic risk profile ${ }^{12,35)}$. Moreover, regular physical activity increases $\mathrm{CRF}^{36)}$ and both physical activity and CRF independently increases insulin sensitivity ${ }^{37)}$.

Several studies have reported an inverse association of CRF with obesity and MS. Buchan et al. ${ }^{38)}$ reported a negative association between CRF and cardiometabolic risks such as HDL-C (inverse), LDL-C, HOMA-IR, systolic BP, and levels of TG, interleukin-6, C-reactive protein, and adiponectin. Ekelund et al. ${ }^{39)}$ reported a negative association between CRF and metabolic risk factors (WC, BP, and levels of fasting glucose, insulin, TG, HDL-C). In addition, LaMonte et al. ${ }^{17)}$ reported a negative association between CRF and the incidence of MS. The result of our study also showed a negative association between CRF and obesity variables such as BMI, WC, and WHtR (all $P=0.00)$. Although the statistical significance varied in each group, we observed a negative association of CRF with BP, FBG, and TG but a positive association with HDL. Thus, higher CRF may be considered as helpful in preventing obesity and MS.

This study has a few limitations. First, since the study subjects were recruited from only elementary school 4 th grade male and female and male-middle school 1st grade students. Thus they do not represent the entire Korean children and adolescents. Second, blood test was performed in 18\% (35 of 193), 28\% (53 of 189 ), and $30 \%$ (139 of 461) of the students in the E4M, E4F, and M1M, indicating only $27 \%$ (227 of 843 ) of the total study population. Third, the pubertal status was not measured in all subjects. Assessment taken at an accurate state of puberty would have allowed a more precise analysis of the metabolic risk factors and obesity in this study.

In conclusion, the findings of the present study support previous findings showing the inverse association between CRF and obesity and metabolic risk factors in children and adolescent. Further studies are needed to establish the relationship between the CRF and obesity across different ages, genders and regions. Also longitudinal or prospective study for relationship between physical fitness and MS risk factor would be needed. Therefore, we suggest that improvement in CRF through regular physical activity would be an important method for reducing the metabolic risks of childhood obesity.

\section{Conflict of interest}

No potential conflict of interest relevant to this article was reported.

\section{Acknowledgments}

This research was supported by the R\&D Program for Society of the National Research Foundation (NRF) funded by the Ministry of Science, ICT \& Future Planning (NRF2013M3C8A2A02078507).

\section{References}

1. Han JC, Lawlor DA, Kimm SY. Childhood obesity. Lancet 2010;375:1737-48.

2. Stewart L. Childhood obesity. Medicine 2011;39:42-4.

3. Oh K, Jang MJ, Lee NY, Moon JS, Lee CG, Yoo MH, et al. Prevalence and trends in obesity among Korean children and adolescents in 1997 and 2005. Korean J Pediatr 2008; 51:950-5.

4. Buchan DS, Boddy LM, Young JD, Cooper SM, Noakes TD, Mahoney C, et al. Relationships between cardiorespiratory and muscular fitness with cardiometabolic risk in adole- 
scents. Res Sports Med 2015;23:227-39.

5. Whitaker RC, Wright JA, Pepe MS, Seidel KD, Dietz WH. Predicting obesity in young adulthood from childhood and parental obesity. N Engl J Med 1997;337:869-73.

6. Jeon YJ, Jung IA, Kim SH, Cho WK, Jeong SH, Cho KS, et al. Serum ferritin level is higher in male adolescents with obesity: results from the Korean National Health and Nutrition Examination Survey 2010. Ann Pediatr Endocrinol Metab 2013;18:141-7.

7. Barlow SE; Expert Committee. Expert committee recommendations regarding the prevention, assessment, and treatment of child and adolescent overweight and obesity: summary report. Pediatrics 2007;120 Suppl 4:S164-92.

8. Cali AM, Caprio S. Obesity in children and adolescents. J Clin Endocrinol Metab 2008;93(11 Suppl 1):S31-6.

9. Sothern MS. Exercise as a modality in the treatment of childhood obesity. Pediatr Clin North Am 2001;48:9951015.

10. Deforche B, Lefevre J, De Bourdeaudhuij I, Hills AP, Duquet W, Bouckaert J. Physical fitness and physical activity in obese and nonobese Flemish youth. Obes Res 2003;11:43441.

11. Kim JW, Seo DI, Swearingin B, So WY. Association between obesity and various parameters of physical fitness in Korean students. Obes Res Clin Pract 2013;7:e67-e74.

12. Caspersen CJ, Powell KE, Christenson GM. Physical activity, exercise, and physical fitness: definitions and distinctions for health-related research. Public Health Rep 1985;100:126-31.

13. Huttunen NP, Knip M, Paavilainen T. Physical activity and fitness in obese children. Int J Obes 1986;10:519-25.

14. Pongprapai S, Mo-suwan L, Leelasamran W. Physical fitness of obese school children in Hat Yai, southern Thailand. Southeast Asian J Trop Med Public Health 1994;25:354-60.

15. Minck MR, Ruiter LM, Van Mechelen W, Kemper HC, Twisk JW. Physical fitness, body fatness, and physical activity: The Amsterdam Growth and Health Study. Am J Hum Biol 2000;12:593-9.

16. Kumagai S, Kai Y, Nagano M, Zou B, Kishimoto H, Sasaki H. Relative contributions of cardiorespiratory fitness and visceral fat to metabolic syndrome in patients with diabetes mellitus. Metab Syndr Relat Disord 2005;3:213-20.

17. LaMonte MJ, Barlow CE, Jurca R, Kampert JB, Church TS, Blair SN. Cardiorespiratory fitness is inversely associated with the incidence of metabolic syndrome: a prospective study of men and women. Circulation 2005;112:505-12.

18. Baek SH, Lee SE, Choi SW. The relationships between the obesity index, and physical fitness and arteriosclerosis factors on elementary school students. Korean J Phys Educ 2011;50;447-53.

19. Li C, Ford ES, Mokdad AH, Cook S. Recent trends in waist circumference and waist-height ratio among US children and adolescents. Pediatrics 2006;118:e1390-8.

20. Speiser PW, Rudolf MC, Anhalt H, Camacho-Hubner C, Chiarelli F, Eliakim A, et al. Childhood obesity. J Clin
Endocrinol Metab 2005;90:1871-87.

21. Zimmet P, Alberti KG, Kaufman F, Tajima N, Silink M, Arslanian S, et al. The metabolic syndrome in children and adolescents: an IDF consensus report. Pediatr Diabetes 2007;8:299-306.

22. Ministry of Education. 2009 Year method for physical fitness test. Seoul: Ministry of Education, 2009.

23. Ortega FB, Artero EG, Ruiz JR, Vicente-Rodriguez G, Bergman P, Hagstromer M, et al. Reliability of healthrelated physical fitness tests in European adolescents. The HELENA Study. Int J Obes (Lond) 2008;32 Suppl 5:S49-57.

24. Moliner-Urdiales D, Ruiz JR, Vicente-Rodriguez G, Ortega FB, Rey-Lopez JP, Espana-Romero V, et al. Associations of muscular and cardiorespiratory fitness with total and central body fat in adolescents: the HELENA study. Br J Sports Med 2011;45:101-8.

25. Park J, Hilmers DC, Mendoza JA, Stuff JE, Liu Y, Nicklas TA. Prevalence of metabolic syndrome and obesity in adolescents aged 12 to 19 years: comparison between the United States and Korea. J Korean Med Sci 2010;25:75-82.

26. Lim H, Xue H, Wang Y. Association between obesity and metabolic co-morbidities among children and adolescents in South Korea based on national data. BMC Public Health 2014;14:279.

27. Shim E, Yang YK. 4th-grade elementary-school children's body image and dietary habits according to body mass index. J Nutr Health 2014;47:287-99.

28. Shin YA, Shin YJ, Park JK, Park J. The comparison of the cutoff definition for diagnosing overweight and obesity among middle and high school students in Seoul. Korean J Obes 2011;20:65-74.

29. Malina RM, Beunen GP, Classens AL, Lefevre J, Vanden Eynde BV, Renson R, et al. Fatness and physical fitness of girls 7 to 17 years. Obes Res 1995;3:221-31.

30. Buchan DS, Young JD, Boddy LM, Baker JS. Independent associations between cardiorespiratory fitness, waist circumference, BMI, and clustered cardiometabolic risk in adolescents. Am J Hum Biol 2014;26:29-35.

31. Artero EG, España-Romero V, Ortega FB, Jimenez-Pavon D, Ruiz JR, Vicente-Rodriguez G, et al. Health-related fitness in adolescents: underweight, and not only overweight, as an influencing factor. The AVENA study. Scand J Med Sci Sports 2010;20:418-27.

32. Bar-Or O. Physical activity and physical training in childhood obesity. J Sports Med Phys Fitness 1993;33:3239.

33. Pathare N, Haskvitz EM, Selleck M. Comparison of measures of physical performance among young children who are healthy weight, overweight, or obese. Pediatr Phys Ther 2013;25:291-6.

34. Hills AP, Hennig EM, Byrne NM, Steele JR. The biomechanics of adiposity--structural and functional limitations of obesity and implications for movement. Obes Rev 2002;3:35-43.

35. Barlow SE, Dietz WH. Obesity evaluation and treatment: 
Expert Committee recommendations. The Maternal and Child Health Bureau, Health Resources and Services Administration and the Department of Health and Human Services. Pediatrics 1998;102:E29.

36. Irwin ML, Yasui Y, Ulrich CM, Bowen D, Rudolph RE, Schwartz RS, et al. Effect of exercise on total and intraabdominal body fat in postmenopausal women: a randomized controlled trial. JAMA 2003;289:323-30.

37. Imperatore G, Cheng YJ, Williams DE, Fulton J, Gregg EW. Physical activity, cardiovascular fitness, and insulin sensitivity among U.S. adolescents: the National Health and
Nutrition Examination Survey, 1999-2002. Diabetes Care 2006;29:1567-72.

38. Buchan DS, Young JD, Boddy LM, Malina RM, Baker JS. Fitness and adiposity are independently associated with cardiometabolic risk in youth. Biomed Res Int 2013;2013: 261698.

39. Ekelund U, Anderssen SA, Froberg K, Sardinha LB, Andersen LB, Brage S, et al. Independent associations of physical activity and cardiorespiratory fitness with metabolic risk factors in children: the European youth heart study. Diabetologia 2007;50:1832-40. 